\title{
Incidental Renal Disorders Found at Necropsies of Violent Death Victims
}

\author{
Obiorah Christopher Chinedu ${ }^{1, *}$, and Preye Opuogidi Edi ${ }^{2}$ \\ ${ }^{1}$ Department of Anatomical pathology, University of Port Harcourt Teaching Hospital, Port Harcourt, Nigeria \\ ${ }^{2}$ Department of Haematology, Blood transfusion and Immunology, University of Port Harcourt, Nigeria
}

*Corresponding author: Obiorah Christopher Chinedu, Department of Anatomical pathology, University of Port Harcourt Teaching Hospital, Port Harcourt, Nigeria, Phone: +234-7030473512; E-mail: Christopher.obiorah@uniport.edu.ng

Received: 03 Jun, 2019 | Accepted: 22 Jul, 2019 | Published: 29 Jul, 2019

Citation: Obiorah CC, Edi PO (2019) Incidental Renal Disorders Found at Necropsies of Violent Death Victims. Int J Nephrol Kidney Fail 5(2): dx.doi.org/10.16966/2380-5498.176

Copyright: (C) 2019 Obiorah CC, et al. This is an open-access article distributed under the terms of the Creative Commons Attribution License, which permits unrestricted use, distribution, and reproduction in any medium, provided the original author and source are credited.

\begin{abstract}
Background: The burden of CKD in our environment remains high while biopsy uptake is low, making for high level of uncertainty in the morphologic characterization of renal disorders.

Aim: To evaluate kidney necropsy tissues of violent death victims, asymptomatic of renal disorders, with a view to detecting lesions of clinical interest and determining the morphologic features of such lesions. Also to review the literature for silent conditions that advances the course of CKD.

Materials and Methods: Prospective cohort study carried out on kidney necropsy tissues of violent death victims who in their antemortem states were asymptomatic of renal disorders. Subjects were firearm and road traffic accident victims irrespective of gender and age brought to UPTH morgue in January 2017, whose close relatives consented. Information confirming that decedents were asymptomatic of a renal disorder was obtained from deceased's close relatives. Necropsy tissues were processed using standard operating procedures for histopathology of renal biopsies, and slides were read by the authors using light microscopy only.

Results: Forty-three tissues were collected-41 males and 2 females. Mean and peak ages were 29.3 (4.9) and 21-30 years with 25/43 (58.1\%). Twenty cases (46.5\%) showed glomerular pathologies composed of $18.6 \%$ FSGS and $27.9 \%$ MPGN. Twenty three cases (53.5\%) were devoid of histologic evidence of glomerular injury. All cases showed evidence of variable degrees of acute tubular injury with ten cases (23.3\%) showing PAS positive casts. Four cases (two each from FSGS and MPGN) displayed chronic interstitial nephritis with mild fibrosis. There was thickening of the arteriolar tunica media in 12 bodies (27.9\%).

Conclusion: Prevalence of asymptomatic CKD is very high among the youths of our locality. Glomerular lesions constitute common pathogenetic bases unlike tubulointerstitial and vascular lesions which were uncommon. Enunciating measures that targeted the youths aimed at reducing rate of smoking and abuse of common analgesics like paracetamol as well as measures that will improve the overall socioeconomic status and encourage routine medical examinations may reverse the upward trend of asymptomatic CKD among our youths.
\end{abstract}

Keywords: Necropsy; Chronic kidney disease; Youths; Port Harcourt; Nigeria

\section{Introduction}

Chronic Kidney Diseases (CKD) often progress to End Stage Renal Disease (ESRD), which require renal replacement therapy. The high functional reserve of the kidney accounts for the asymptomatic state of patients with anatomic lesions. The long preclinical latency underlies the consideration of screening of asymptomatic individuals for CKD as potentially useful means of early detection [1]. For example, Serum creatinine and GFR may remain normal even with the loss of up to $50 \%$ of nephron function in a disease process [2]. Thus, the reported $8-10 \%$ hospital admissions rate of CKD in Nigeria is gross under reportage as it is well known that CKD is under-recognized and under-diagnosed [3]. This explains why in many situations, by the time patients present with overt symptoms and signs, necessitating renal biopsy performance and evaluation, the lesion may be advanced and at end stage. This is worse in our environment where empirical treatment of nephrology patients' overrides biopsy based treatment [4,5]. Different authors have put forward research findings which suggest that age, environmental influence and race are contributory to the development and progression of CKD. De Mulder PH, et al. [6] and Rowe JW, et al. [7] in their separate reports observed gradual loss of renal function with age while Odenigbo et al reported that the burden of infection and other environmental factors by most developing countries including Nigeria contribute to the broadened spectrum of chronic kidney diseases [6-8]. Besides, other workers have documented that $\mathrm{CKD}$ is more common among people of black race than other races, and that ESRD constitutes the leading cause of death in Africa [9-11]. Also, ESRD causes an enormous socio-economic burden on our society and the health care systems, 
especially in the face of a deplorable economy and pervading poverty among the majority of the populace [8].

Progression of many forms of renal injury toward end-stage disease results in nonspecific chronic changes that obscure the nature of the original pathologic process [12]. So pathologic evaluation of biopsies of asymptomatic patients' not only enables precise diagnosis but identifies the primary compartment involved. This constitutes an important guide for clinicians in empiric treatment of renal diseases especially in our centre with paucity of renal biopsies in spite of the high burden of renal diseases. This study therefore high lights and documents the morphology of early renal lesions which ordinarily would progress among asymptomatic individuals in Port Harcourt, as well as reviews the literature for silent conditions that advance the course of CKD.

\section{Materials and Methods}

The study was conducted at the renal unit of the Anatomical Pathology Department of the University of Port Harcourt Teaching Hospital (UPTH), Port Harcourt, and Rivers State, Nigeria. It was a prospective cohort study carried out on embalmed bodies of violent death victims who were asymptomatic of renal disease in their lifetimes. Violent deaths in this study referred to sudden deaths not preceded by any illness, caused by physical harm from fire arms or road traffic accidents. Violent death victims brought to UPTH morgue in the month of January 2017 whose relatives volunteered information and gave written consent were recruited into the study. Through a structured questionnaire, decedents were confirmed not to have had renal disease symptoms in their lifetimes by their spouses, parents, or close siblings who lived with them. Specifically, questions relating to basic but not exclusive symptoms of kidney diseases like, ankle or leg swelling, puffiness around the eyes, or whole face, unexplained tiredness, unprovoked vomiting, persistent passage of foamy or bloody urine, frequent urination, reduced urine volume, etc., were asked in the questionnaire. The decedents were also confirmed not to have consulted nephrologists or urologists in their lifetime. Demographic and antemortem clinical information were also obtained. Cases whose relations declined consent and those who died following sicknesses were excluded from the study.

Open necropsy renal tissues were taken from the bodies during the ensuing medicolegal autopsies or needle biopsies (cases for which consents were received but no dates were scheduled for autopsy). Necropsy tissues were further fixed in $10 \%$ neutral buffered formalin and processed using standard operating procedures for histopathology of renal biopsies, including: taking thin serial sections of the paraffin embedded tissue blocks and staining with hematoxylin and eosin, periodic acid schiff, Jones methenamine silver and Masson's trichrome. Positive tissue controls were used for the special stains. The resultant slides were read by the lead author who is a nephropathologist. The minimal histological light microscopic diagnostic criteria for MPGN included: segmental or global hypercellularity occasioned by proliferation of mesangial and endothelial cells with variable degrees of expansion of mesangial matrix, thickening of the peripheral capillary walls with or without mesangial interposition and double contour formation. For FSGS, the criteria included: variable degrees of focal and segmental sclerotic lesions adhering to the Bowman's capsule with obliteration of associated glomerular capillaries. Data was processed using SPSS version 23 and presented as simple descriptive tables and figures.

The study was approved by the research ethics committee of the University of Port Harcourt Teaching Hospital.

\section{Results}

Forty-three necropsy tissues were collected from victims of violent deaths of which thirty two were open necropsy tissues collected in the course of medicolegal autopsies of the bodies while eleven were per cutaneous needle necropsy tissues collected without autopsies (Figure 1). There were 41 males and 2 females (Figure 2). The age range and mean of the decedents were 11-43 years and $29.3 \pm 4.9$ years. The peak age group was 21-30 years with 28 cases (65.1\%) (Table $1)$. Twenty cases $(46.5 \%)$ showed obvious subclinical glomerular pathologies. Twelve cases (27.9\%) showed glomerular injury patterns consistent with Mesangial Proliferative Glomerulonephritis (MPGN) while 8 cases (18.6\%) showed injury patterns consistent with Focal Segmental Glomerulosclerosis (FSGS). Twenty three cases $(53.5 \%)$ were devoid of histologic evidence of glomerular injury (Table 2). All cases showed evidence of variable degrees of Acute Tubular Injury (ATI), with majority- 24 cases (55.8\%) being of moderate degree while 14 cases $(32.6 \%)$ were mild and 5 cases $(11.6 \%)$ were severe (Table 2). Ten (23.3\%) of the cases showed PAS positive casts, while 33 cases (76.7\%) showed no casts. Four cases (two each from FSGS and MPGN) displayed histologic features of chronic interstitial nephritis with mild fibrosis. The blood vessels (arterioles) of 12 bodies (27.9\%) showed thickening of the tunica media while the remaining 31 cases $(72.1 \%)$ did not show vascular abnormality.

\section{Types of tissue biopsy}

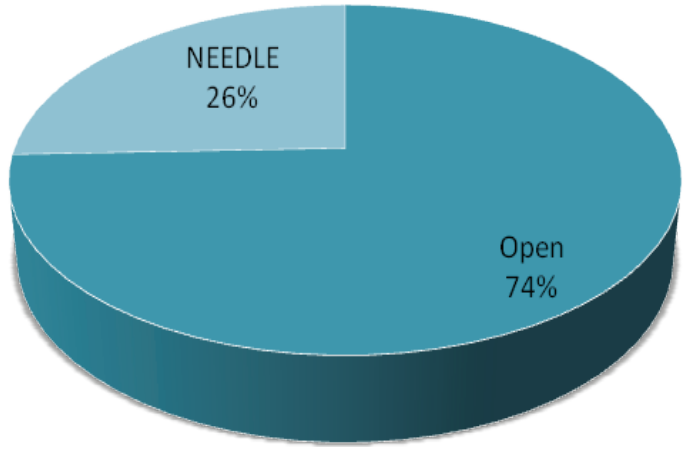

Figure 1: Types of tissue biopsy.

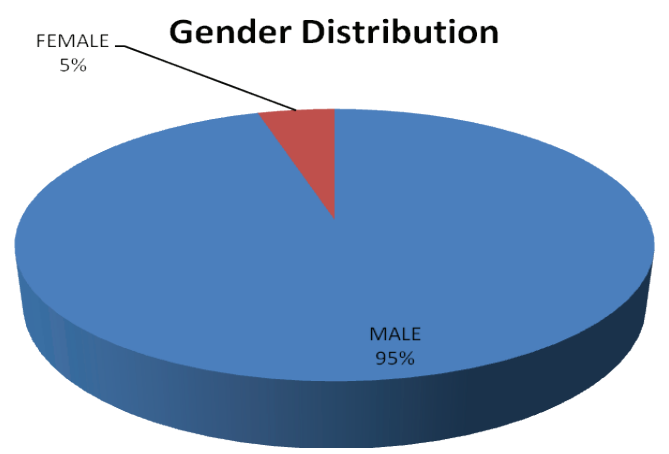

Figure 2: Gender Distribution. 
Table 1: Age distribution.

\begin{tabular}{|c|c|c|c|c|c|c|c|c|}
\hline \multirow{3}{*}{ Age Group } & \multicolumn{6}{|c|}{ Diagnosis } & \multirow{2}{*}{\multicolumn{2}{|c|}{ Total }} \\
\hline & \multicolumn{2}{|c|}{ FSGS } & \multicolumn{2}{|c|}{ MPGN } & \multicolumn{2}{|c|}{ Normal Glomeruli } & & \\
\hline & $\mathbf{N}$ & $\%$ & $\mathbf{N}$ & $\%$ & $\mathbf{N}$ & $\%$ & $\mathbf{N}$ & $\%$ \\
\hline $11-20$ & 1 & 12.5 & 1 & 8.3 & 0 & 0.0 & 2 & 4.7 \\
\hline $21-30$ & 5 & 62.5 & 8 & 66.7 & 15 & 65.2 & 28 & 65.1 \\
\hline $31-40$ & 2 & 25 & 2 & 16.7 & 8 & 34.8 & 12 & 27.9 \\
\hline $41-50$ & 0 & 0.0 & 1 & 8.3 & 0 & 0.0 & 1 & 2.3 \\
\hline Total & 8 & 100 & 12 & 100 & 23 & 100 & 43 & 100 \\
\hline
\end{tabular}

Table 2: Frequency of acute tubular injury.

\begin{tabular}{|c|c|c|c|c|c|c|c|c|}
\hline Diagnosis & Mild ATI & Percentage (\%) & Moderate ATI & Percentage (\%) & Severe ATI & Percentage (\%) & Total & $\begin{array}{c}\text { Percentage }(\%) \text { of } \\
\text { total }\end{array}$ \\
\hline FSGS & 3 & 21.4 & 5 & 20.8 & 0 & 0 & 8 & 18.6 \\
\hline MPGN & 4 & 28.6 & 8 & 33.3 & 0 & 0 & 12 & 27.9 \\
\hline Normal & 7 & 50 & 11 & 45.8 & 5 & 100 & 23 & 53.5 \\
\hline Total & 14 & 100 & 24 & 100 & 5 & 100 & 43 & 100 \\
\hline
\end{tabular}

\section{Discussion}

Patients with early or mild renal disorders are often asymptomatic and therefore get on with their daily activities [13]. Consistent with this fact, the subjects of this study were apparently healthy and on their various activities for daily living in the course of which they encountered sudden violent deaths. They died from injuries sustained from gun-shots or road traffic accidents. The findings of this work which are anatomic and structural and therefore indicate high prevalence of latent renal disorders in our environment. As much as $46.5 \%$ of the necropsies had significant pathologic lesions. This finding corroborates previous clinical studies in our environment which showed a high rate of asymptomatic CKD. The latter may be a consequence of the reported high prevalence rate of risk factors for CKD like systemic hypertension, obesity and proteinuria in different studies carried out among children and adults in Port Harcourt [1416]. Given the documented progressive course of CKD, the subjects would therefore likely progress to End Stage Renal Disease (ESRD) [17-19]. Previous studies carried out in our centre by Wachukwu CM, et al. [16] showed high mortality from ESRD.

To partly deal with the high morbidity and mortality associated with ESRD generally, screening studies in nephrology practice such as ours are rife. However, most of the published works available to us were based on simple procedures like urinalysis, blood pressure measurement or ultrasonography which are limited in clinical application because the diagnostic value of such studies is not definitive [20-23]. Histologic evaluation remains the gold standard in the definitive diagnoses of parenchymal lesions [24].

In a resource-poor setting with high burden of CKD/ESRD such as ours, emphasis should be laid on CKD prevention and interruption of progression of renal lesions. This is achievable through early diagnosis and implementation of lifestyle changes [3]. In view of the paucity of renal biopsies in our environment, screening necropsy study on apparently normal individuals provides a good alternative approach to morphologic characterization of lesions responsible for latent CKD.

The Subjects of this study were all young (age range of 11-43 years, mean of 29 years and peak age group of 21-30 years). Since the subjects were randomly selected, the predominance of young person's suggests that $\mathrm{CKD}$ is rife among the young people within our society. Consistent with this finding is an earlier clinical study in our centre which reported that CKD is common among the younger age groups who were in the most productive phases of their lives, with the majority being victims of hypertension [25]. Furthermore, hypertension not only has a high prevalence in our environment but constitutes the leading cause of natural deaths [26]. Although the fact that violent deaths have been documented as the commonest mode of deaths among young people in our environment may be a contributory factor to the overriding number of young people in this study [27]. The high prevalence of infections/infestations especially among childhood that predisposes to Chronic Glomerulonephritis (CGN) has been entertained as possible reasons for the younger age of patients with CKD/ESRD in Nigeria $[10,28]$. The associated morbidity and mortality of young people from CKD/ERSD has far reaching negative psychological, social and economic implications for our society [3]. On the contrary, CKD is more common among the elderly in the United States and other Western countries $[29,30]$.

The finding of varying degrees of glomerular injury in $46.5 \%$ of the decedents gives direct evidence of $\mathrm{CKD}$, since these pathologic lesions would result in the reduction of renal function especially the Glomerular Filtration Rate (GFR). According to the American National Kidney Foundation Kidney Disease Outcomes Quality Initiative (NKF KDOQI tm), CKD could be diagnosed solely on the basis of GFR $<60 \mathrm{ml} / \mathrm{min} / 1.73 \mathrm{~m}^{2}$ [31]. Evaluating clinical parameters of the subjects were outside the scope of this study.

The morphologic lesions in this study are almost entirely involving 
the glomeruli. Consistent with our finding, in most morphologic studies conducted early in the course of renal diseases, glomerular injuries predominated over injuries of the other compartments. It is plausible that the delicate nature, strategic location of the glomerulus in the nephron and the dynamic physical forces it withstands in its plasma filtration process as well as the occasional noxious components of the filtered blood accounts for the predominant involvement of the glomeruli in CKD. As a public health measure, institutionalizing and publicizing measures that will reduce the affectation of glomeruli in disease processes or those that will freeze or reverse lesions behind CKD needs to be articulated.

Consequently, some clinical conditions and lifestyles that are associated with the development of, and progression of CKD are worthy of elucidation with a view to drawing attention to them in order to minimize the negative effects of their scourge in our environment. An American study reported that the presence of diabetes was found to double the risk of developing CKD compared with those without diabetes [32]. Although Diabetes Mellitus (DM) has not been cited as a common predisposing condition for CKD in Nigeria, unlike the Western countries neither did this study ascertain if the decedents were diabetics or not, but it is advocated that policies and mechanisms for early surveillance of DM patients for CKD should be ensured by physicians. Also studies have shown that hypertension is a strong risk factor for CKD among Nigerians [3,14,25]. Therefore, encouraging young asymptomatic people to routinely go for medical check-ups or to at least check their blood pressures would be helpful in detecting cases and allow for further renal function monitoring. Study evidence has been provided that a current or former history of smoking (at five years before survey) is a significant risk factor for CKD development and progression [33-35]. In their review article, Oyewole BK, et al. [36] reported a prevalence rate of up to $32.5 \%$ and noted that smoking poses a huge burden to Nigerian youths. Therefore, smoking which is common practice among young persons in our society should be discouraged through the imposition of more tax levies on cigarette importation as well as the enforcement of other laws of the society that discourage public place smoking and its attendant passive effect on non-smokers

Contrary to popular opinion, long term use of Non-Steroidal AntiInflammatory Drugs (NSAID) in prescribed doses was shown not to be a significant risk factor for CKD unlike use of paracetamol $[37,38]$. This is important because a majority of our young people is engaged in physically demanding jobs and is therefore dependent on analgesics for job sustenance. This trend deserves to be checked, especially the abuse of paracetamol which is largely seen as not having a deleterious effect on the kidney.

It has also been shown that lower socioeconomic status and lower level of educational attainment were significant risk factors for CKD [39]. In our society, people of low socioeconomic status abound especially among the youths because of the dearth of jobs, hence the documentation that $60 \%$ of Nigerians live below poverty line [40]. Therefore, it is arguable that the pervading high level of unemployment and attendant poverty in Nigeria is a predisposition to the development of CKD.

It is understandable that in all of the cases, tubular injuries of various degrees were present-14 cases (32.6\%) of mild, 24 cases $(55.8 \%)$ of moderate and 5 cases $(11.6 \%)$ of severe. This is because hemorrhagic shock was the mechanisms of death in all cases.

Although most studies on the prevalence of CKD/ESRD showed predominance of males over females, no study reported such a male skew as we observed in this study. This extreme gender imbalance may therefore be a reflection of the predispositions of males to violent deaths than females. This is more plausible than ascribing the gender imbalance to renal diseases in our environment.

The most common glomerular lesion observed in this study was Mesangial Proliferative Glomerulonephritis (MPGN)-constituting $27.9 \%$ of the glomerular lesions. Proliferative glomerulonephritis like MPGN is considered a sequela of the overriding infectious processes inherent in our environment [12]. This is consistent with the reported high prevalence of Chronic Glomerulonephritis (CGN) as the most common cause of CKD in Nigeria [5,10,28,41].

FSGS accounted for $18.6 \%$. Another Nigerian study reported an FSGS prevalence rate of $27.3 \%$ [42]. The prevalence of FSGS according to regions in Africa was highest for West Africa (19.1\%) and lowest in North Africa (13.1\%) [43].

This work was limited by the relatively low number of cases studied, due to resentment of relatives of deceased to give consent for biopsy of deceased kidneys. Also absence of immunoflourescent and electron microscopy to allow for further evaluation of the glomerular diseases precluded some definitive diagnoses which would only be made with the aid of those diagnostic tools. The paucity of similar studies precluded comparison and discussion of findings from such studies. Also, because subjects were not attended to in UPTH during life and the bodies were embalmed prior to biopsy, it was not possible to take blood samples to check for electrolytes and creatinine levels as well as GFR.

\section{Conclusion}

Prevalence of asymptomatic CKD is very high among the youths of our locality. Glomerular lesions constitute common pathogenetic bases unlike tubulointerstitial and vascular lesions which were uncommon. Enunciating measures targeting the youths aimed at reducing rates of smoking and abuse of common analgesics like paracetamol as well as measures that will improve the overall socioeconomic status and encourage routine medical examinations may reverse the upward trend of asymptomatic CKD among our youths.

\section{Acknowledgement}

We wish to thank the relatives of deceased persons who gave consents that enabled this work. Pathologists in the Anatomic pathology department and staff of the mortuary unit of UPTH are thanked for their technical support in the work. We are also thankful to Mrs. Gift Oletu, Martha Akpanumoh and Prof. Ifeoma Anochie for their different supportive roles in this work.

\section{Conflict of Interest Declaration}

We declare that there were no conflicting interests in this work and that funding was by the authors.

\section{References}

1. Berns JS (2014) Routine screening for CKD should be done in asymptomatic adults... selectively. Clin J Am Soc Nephrol 9: 19881992.

2. Liu YW, Su CT, Song EJ, Tsai WC, Li YH, et al. (2015) The role of echocardiographic study in patients with chronic kidney disease. J Formos Med Assoc 114: 797-805.

3. Ulasi II, ljoma CK (2010) The Enormity of Chronic Kidney Disease in Nigeria: The Situation in a Teaching Hospital in South-East Nigeria. J Trop Med 2010: 501957. 
4. Anochie I, Eke F, Okpere A (2006) Childhood nephrotic syndrome: change in pattern and response to steroids. J Natl Med Assoc 98: 1977-1981.

5. Obiorah CC, Okoro PE (2018) Clinicopathological report of children and young adults with nephrotic syndrome undergoing renal biopsy at workshops in Port Harcourt, Nigeria. Afr J Nephrol 21: 3-7.

6. De Mulder PH, Weissbach L, Jakse G, Osieka R, Blatter J (1996) Gemcitabine: a phase II study in patients with advanced renal cancer. Cancer Chemother Pharmacol 37: 491-495.

7. Rowe JW, Andres R, Tobin JD, Norris AH, Shock NW (1976) The effect of age on creatinine clearance in men: a cross-sectional and longitudinal study. J Gerontol 31: 155-163.

8. Odenigbo C, Oguejiofor O, Onwubuya E, Onwukwe CH (2014) The prevalence of chronic kidney disease in apparently healthy retired subjects in asaba, Nigeria. Ann Med Health Sci Res 4: S128-S132.

9. McClellan WM, Knight DF, Karp H, Brown WW (1997) Early detection and treatment of renal disease in hospitalized diabetic and hypertensive patients: Important differences between practice and published guidelines. Am J Kidney Dis 29: 368-375.

10. Alebiosu CO, Ayodele OE (2005) The global burden of chronic kidney disease and the way forward. Ethn Dis 15: 418-423.

11. Odubanjo MO, Okolo CA, Oluwasola AO, Arije A (2011) End-stage renal disease in Nigeria: An overview of the epidemiology and the pathogenetic mechanisms. Saudi J Kidney Dis Transpl 22: 1064-1071.

12. Jennette JC, D'Agati VD, Olson JL, Silva FG (2014) Heptinstall's Pathology of the Kidney. Wolters Kluwer Health.

13. Obrador GT (2008) Chronic Renal Failure \& the Uremic Syndrome. In: Lerma E, Berns JS, Nissenson AR (eds) Current Diagnosis \& Treatment: Nephrology \& Hypertension. McGraw Hill Professional, USA.

14. Akpa MR, Unamba NN (2017) Asymptomatic Chronic Kidney Disease and Correlates in Untreated Hypertensive Patients Attending a Referral Hospital in Southern Nigeria. Clin Pract 6: 9-13.

15. Okere P, Ezeofor SN, Iloanusi NI, Ibinaiye PO, Okoye IJ (2015) Sonographic analysis of adult polycystic kidney disease: retrospective data from South-East Nigeria. Niger J Clin Pract 18: 178-182.

16. Wachukwu CM, Emem-Chioma PC, Wokoma FS, Oko-Jaja RI (2015) Prevalence of risk factors for chronic kidney disease among adults in a university community in southern Nigeria. Pan Afr Med J 21: 120.

17. Robertson J, Seguin MA (2006) Renal Disease-Case-Based Approach to Acute Renal Failure, Chronic Renal Failure and Protein-Losing Nephropathy. IDEXX Laboratories, USA.

18. Viau A, El Karoui K, Laouari D, Burtin M, Nguyen C, et al. (2010) Lipocalin 2 is essential for chronic kidney disease progression in mice and humans. J Clin Invest 120: 4065-4076.

19. Zhang JJ, Ma XX, Hao L, Liu LJ, Lv JC, et al. (2015) A systematic review and meta-analysis of outcomes of pregnancy in CKD and CKD outcomes in pregnancy. Clin J Am Soc Nephrol 10: 1964-1978.

20. Odetunde OI, Odetunde OA, Neboh EE, Okafor HU, Njeze NR, et al. (2015) Urinary screening for asymptomatic renal disorders in preschool children in Enugu metropolis, South-east Nigeria: Useful or useless. Saudi J Kidney Dis Transpl 26: 1241-1245.

21. Ikimalo FE, Eke FU, Nkanginieme KEO, Ikimalo J (2003) Urinary screening for detection of asymptomatic haematuria and proteinuria in children in urban and periurban schools in Port Harcourt. Niger J Paediatr 30: 1-6.
22. Avni EF, Vandemerckt C, Braude P, Detemmerman D, Van Gansbeke $D$, et al. (1988) Sonographic evaluation of renal inflammatory diseases in children. World J Urol 6: 18-21.

23. Kazancioğlu R (2011) Risk factors for chronic kidney disease: An update. Kidney Int Suppl 3: 368-371.

24. Goldblum JR, Lamps LW, Myers JL, McKenney JK (2017) Rosai and Ackerman's Surgical Pathology. $11^{\text {th }}$ edition, Elsevier Health Sciences.

25. Nalado AM, Abdu A, Muhammad H, Abdu A, Sakajiki AM, et al. (2012) Prevalence of risk factors for chronic kidney disease among civil servants in Kano. Niger J Basic Clin Sci 9: 70-74.

26. Obiorah CC, Amakiri CNT (2012) Systemic Analysis of Sudden Natural Deaths at Braithwaite Memorial Specialist Hospital Port Harcourt, Nigeria. Nigerian Health Journal 12: 47-51.

27. Obiorah CC, Amakiri CN (2014) Autopsy study of traumatic/violent deaths in Rivers State of Nigeria. Port Harcourt Med J 8: 40-49.

28. Naicker S (2013) End-stage renal disease in Sub-Saharan Africa. Kidney Int Suppl 3: 161-163.

29. Jungers P, Choukroun G, Robino C, Massy ZA, Taupin P, et al. (2000) Epidemiology of end-stage renal disease in the lle-de-France area: $A$ prospective study in 1998. Nephrol Dial Transplant 15: 2000-2006.

30. US Renal Data System (2005) USRDS 2005 Annual Data Report: Atlas of End-Stage Renal Disease in the United States. National Institutes of Health, National Institute of Diabetes and Digestive and Kidney Diseases, Bethesda, MD, USA.

31. National Kidney Foundation (2002) K/DOQI clinical practice guidelines for chronic kidney disease: evaluation, classification, and stratification. Am J Kidney Dis 39: S1-S266.

32. Foley RN, Murray AM, Li S, Herzog CA, McBean AM, et al. (2005) Chronic kidney disease and the risk for cardiovascular disease, renal replacement, and death in the United States Medicare population, 1998 to 1999. J Am Soc Nephrol 16: 489-495.

33. Ejerblad E, Fored CM, Lindblad P, Fryzek J, Dickman PW, et al (2004) Association between smoking and chronic renal failure in a nationwide population-based case-control study. J Am Soc Nephrol 15: $2178-2185$

34. Orth SR, Schroeder T, Ritz E, Ferrari P (2005) Effects of smoking on renal function in patients with type 1 and type 2 diabetes mellitus. Nephrol Dial Transplant 20: 2414-2419.

35. Warmoth L, Regalado MM, Simoni J, Harrist RB, Wesson DE (2005) Cigarette smoking enhances increased urine albumin excretion as a risk factor for glomerular filtration rate decline in primary hypertension. Am J Med Sci 330: 111-119.

36. Oyewole BK, Animasahun VJ, Chapman HJ (2018) Tobacco use in Nigerian youth: A systematic review. PloS One 13: e0196362.

37. Curhan GC, Knight EL, Rosner B, Hankinson SE, Stampfer MJ (2004) Lifetime non-narcotic analgesic use and decline in renal function in women. Arch Intern Med 164: 1519-1524.

38. Kurth T, Glynn RJ, Walker AM, Rexrode KM, Buring JE, et al. (2003) Analgesic use and change in kidney function in apparently healthy men. Am J Kidney Dis 42: 234-244.

39. Fored CM, Ejerblad E, Fryzek JP, Lambe M, Lindblad P, et al. (2003) Socio-economic status and chronic renal failure: A population-based case-control study in Sweden. Nephrol Dial Transplant 18: 82-88. 
40. Central Intelligence Agency (2005) The World Factbook. Nigeria.

41. Obiagwu PN, Aliyu A, Atanda AT (2014) Nephrotic syndrome among children in Kano: A clinicopathological study. Niger J Clin Pract 17: 370-374.

42. Ojogwu LI, Ukoli FA (1993) A follow up study of adult nephrotic syndrome in Nigerians: Outcome and predictors of endstage renal failure. Afr J Med Med Sci 22: 43-50.

43. Okpechi IG, Ameh OI, Bello AK, Ronco P, Swanepoel CR, et al. (2016) Epidemiology of histologically proven glomerulonephritis in Africa: A systematic review and meta-analysis. PLoS One 11: e0152203. 